\title{
Effect of Magnesium Fluoride on Hydrogenation Properties of Magnesium Hydride
}

\author{
Pragya Jain ${ }^{1,2}$, Viney Dixit ${ }^{1}$, Ankur Jain ${ }^{3}$, Onkar N. Srivastava ${ }^{1}$ and Jacques Huot ${ }^{2, *}$ \\ Received: 12 July 2015 ; Accepted: 15 October 2015 ; Published: 4 November 2015 \\ Academic Editor: Craig M. Jensen \\ 1 Hydrogen Energy Centre, Department of Physics, Banaras Hindu University, Varanasi 221 005, India; \\ pragya.2604@gmail.com (P.J.); vinay.dixit28@gmail.com (V.D.); ons@bhu.ac.in (O.N.S.) \\ 2 Hydrogen Research Institute, Université du Québec à Trois-Rivières, Trois-Rivières, QC G9A 5H7, Canada \\ 3 Institute for Advanced Materials Research, Hiroshima University, Higashi-Hiroshima 739-8530, Japan; \\ ankur.j.ankur@gmail.com \\ * Correspondence: jacques.huot@uqtr.ca; Tel.: +1-819-376-5011 (ext. 3576); Fax: +1-819-376-5164
}

\begin{abstract}
A cost effective catalyst is of great importance for consideration of $\mathrm{MgH}_{2}$ as potential hydrogen storage material. In this regard, we investigated the catalytic role of alkaline metal fluoride on the hydrogen storage behavior of $\mathrm{MgH}_{2}$. Samples were synthesized by admixing $5 \mathrm{~mol} \% \mathrm{MgF}_{2}$ into $\mathrm{MgH}_{2}$ powder using planetary ball mill. Hydrogenation measurements made at $335^{\circ} \mathrm{C}$ showed that in comparison to only $70 \%$ absorption by pure $\mathrm{MgH}_{2}$, catalyzed material absorbed $92 \%$ of theoretical capacity in less than $20 \mathrm{~min}$ and desorbed completely in almost the same time. Sorption studies done at lower temperatures revealed that complete absorption at temperature as low as $145^{\circ} \mathrm{C}$ is possible. This is due to uniform distribution of $\mathrm{MgF}_{2}$ nano particles within the $\mathrm{MgH}_{2}$ powder. X-ray diffraction patterns also showed the presence of stable $\mathrm{MgF}_{2}$ phase that does not decompose upon hydrogen absorption-desorption. Cyclic measurements done at $310{ }^{\circ} \mathrm{C}$ showed negligible loss in the overall storage capacity with cycling. These results reveal that the presence of the chemically inert and stable $\mathrm{MgF}_{2}$ phase is responsible for good reversible characteristic and improved kinetics.
\end{abstract}

Keywords: magnesium hydride; magnesium fluoride; hydrogen storage; metal hydrides; kinetics

\section{Introduction}

Magnesium hydride is a potential candidate for hydrogen storage because of its high gravimetric and volumetric capacities. Pure magnesium's low environmental impact and abundant availability makes it very attractive for hydrogen storage application. However, high working temperature and slow kinetics limit its potential as hydrogen storage material for practical applications. Therefore, research is required to circumvent these difficulties and make $\mathrm{MgH}_{2}$ a viable hydrogen storage material. Nano-structuring of $\mathrm{MgH}_{2}$ is one of the most adopted methods to improve the hydrogenation performance [1]. However, this method has a limitation to achieve the nanocrystalline size $(<5 \mathrm{~nm})$ required for destabilization of $\mathrm{MgH}_{2}$ [2].

Further improvements in sorption behaviour have been achieved by adding a wide variety of pure transition metals [3,4], their oxides [5] and halides [6-8]. The remarkable catalytic effect of transition metal oxide, $\mathrm{Nb}_{2} \mathrm{O}_{5}$ has been well reported. However, during cycling at elevated temperatures, reduction of $\mathrm{Nb}_{2} \mathrm{O}_{5}$ occurs with augmentation of $\mathrm{MgO}$ content [5]. Later, it was found that some transition metal halides, such as $\mathrm{FeF}_{3}, \mathrm{CrCl}_{3}, \mathrm{NiF}_{2}, \mathrm{NbCl}_{5}$ and $\mathrm{TiCl}_{3}$ possess better catalytic activity than pure metals or their oxides [6-8]. In the case of halides, Malka et al. [9] showed that fluorides are better catalysts than chlorides for $\mathrm{MgH}_{2}$. Addition of transition metal fluorides during milling helps to lower the hydrogen release temperature and increase the rate of hydrogen uptake 
by $\mathrm{MgH}_{2}$. It has been shown by different groups [7-9] that during milling of $\mathrm{MgH}_{2}$ with transition metal fluorides, the formed $\mathrm{MgF}_{2}$ phase replaces the original oxide layer and provides a reactive and protective fluorinated surface for hydrogen uptake. This compound possesses high affinity with hydrogen because of the F-anion, which weakens the Mg-H bonding and improves the sorption properties [9].

However, not much work has been done on direct use of $\mathrm{MgF}_{2}$ as an additive for $\mathrm{MgH}_{2}$. Ivanov et al. [10] reported that addition of $5 \mathrm{wt} \% \mathrm{MgF}_{2}$ to pure $\mathrm{Mg}$ during milling leads to $5 \mathrm{wt} \%$ hydrogen absorption in over $20 \mathrm{~h}$ but has an insignificant effect on dehydrogenation kinetics of $\mathrm{MgH}_{2}$. Loss in absorption capacity from the second cycle onwards was also observed. Recently, Ma et al. [11] investigated the catalytic effects of $\mathrm{MgF}_{2}$ and $\mathrm{TiH}_{2}$ to understand the kinetic improvements obtained when $\mathrm{MgH}_{2}$ was ball milled with $4 \mathrm{~mol} \% \mathrm{TiF}_{3}$. They reported that sole addition of $6 \mathrm{~mol} \% \mathrm{MgF}_{2}$ has negligible catalytic effect on $\mathrm{MgH}_{2}$ at an operating temperature of $150{ }^{\circ} \mathrm{C}$.

The limited and inconsistent results attained on catalytic effect of $\mathrm{MgF}_{2}$ on $\mathrm{MgH}_{2}$ shows that more work needs to be done to understand this system both from hydrogenation and material perspective. The present work is aimed to investigate the microstructural, morphological and hydrogenation behaviour of $\mathrm{MgH}_{2}$ when $\mathrm{MgF}_{2}$ is used as additive.

\section{Results}

\subsection{Comparison of Undoped and $5 \mathrm{~mol} \% \mathrm{MgF}_{2}$ Doped $\mathrm{MgH}_{2}$ at $335^{\circ} \mathrm{C}$}

The X-ray diffraction (XRD) patterns of $\mathrm{MgH}_{2}$ without and with $5 \mathrm{~mol} \% \mathrm{MgF}_{2}$ prepared by $1 \mathrm{~h}$ ball milling are shown in Figure 1. For the undoped sample, the diffraction pattern peaks are associated with main phase of $\beta-\mathrm{MgH}_{2}$ and some unreacted $\mathrm{Mg}$. There is no evidence of the metastable $\gamma-\mathrm{MgH}_{2}$ phase. This is due to the short milling time and low milling intensity. A broad peak centered at $43^{\circ}$ is attributed to $\mathrm{MgO}$. The crystallite size of $\beta-\mathrm{MgH}_{2}$ is evaluated from Rietveld refinement to be $23.4 \pm 0.3 \mathrm{~nm}$. Milling with $\mathrm{MgF}_{2}$ additive was even more effective for reduction of crystallite size of $\mathrm{MgH}_{2}$ that was evaluated as $10.9 \pm 0.3 \mathrm{~nm}$. During milling there is physical interaction between the different species during the repeating collisions. Therefore, the $\mathrm{MgF}_{2}$ has also some mechanical effect on $\mathrm{MgH}_{2}$. Unfortunately, the alloying of brittle-brittle system is poorly understood [12]. However, from the present experiment it seems that addition of small amount of $\mathrm{MgF}_{2}$ improves crystallite size reduction but the exact mechanism is still unclear.

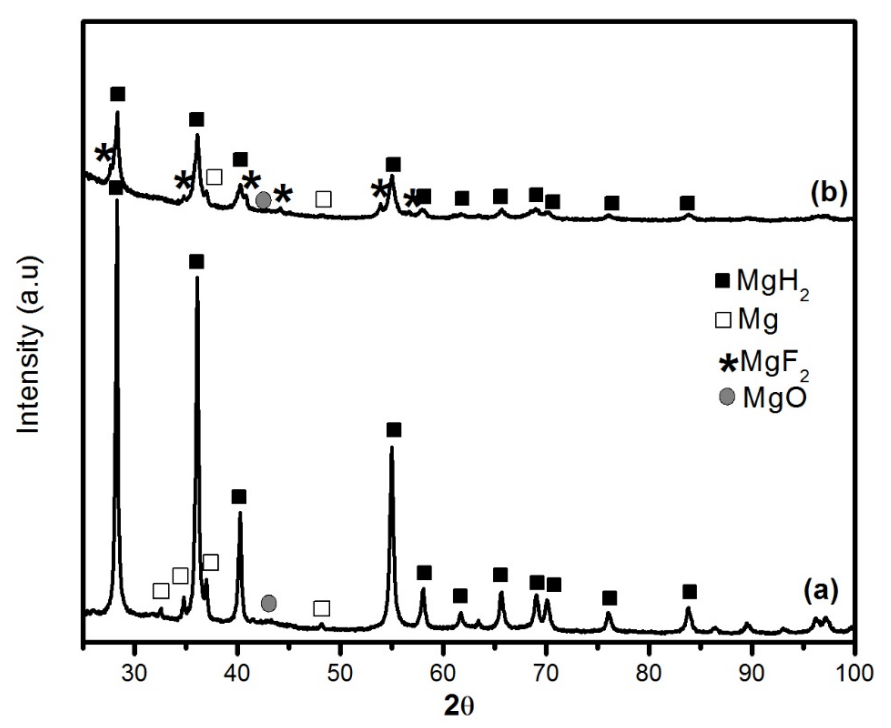

Figure 1. XRD patterns of ball milled samples milled $1 \mathrm{~h}$ : (a) pure $\mathrm{MgH}_{2}$ and (b) $\mathrm{MgH}_{2}+5 \mathrm{~mol} \% \mathrm{MgF}_{2}$. 
In practical applications, desorption will be performed under a pressure of at least $100 \mathrm{kPa}$ of hydrogen. However, in order to study the behaviour of $\mathrm{MgH}_{2}-\mathrm{MgF}_{2}$ system, we decided to fully dehydride the samples after ball milling. Therefore, after milling the samples were completely desorbed at $335{ }^{\circ} \mathrm{C}$ under dynamic vacuum before investigating their hydrogenation properties. Representative hydrogenation and dehydrogenation characteristics are shown in Figure 2.
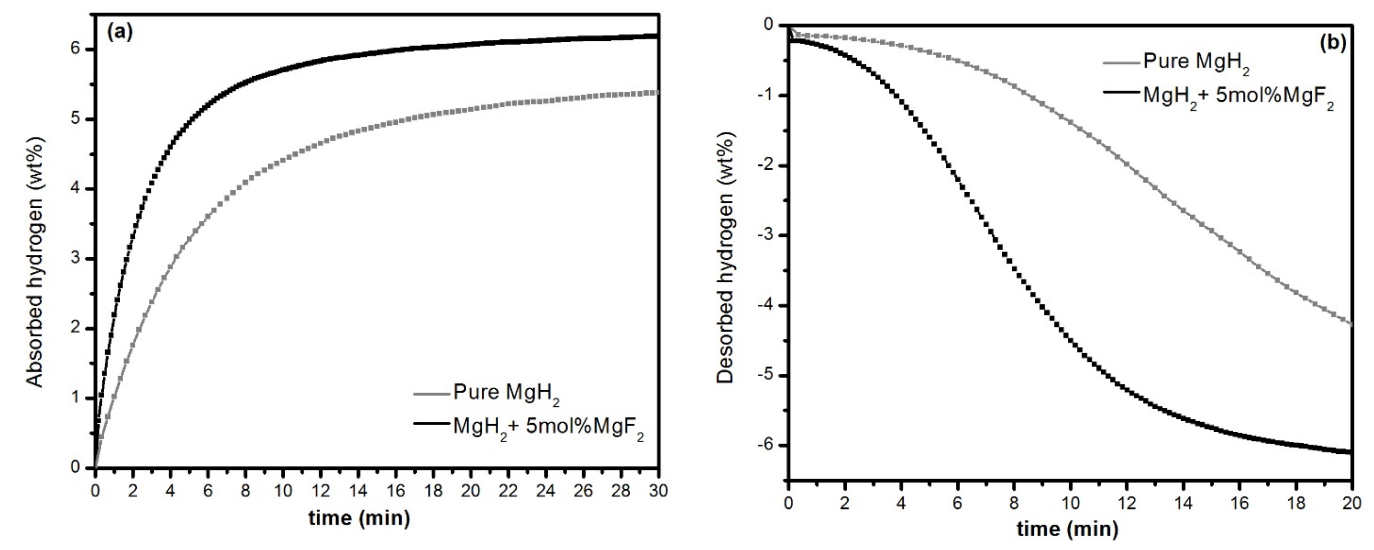

Figure 2. Hydrogen sorption kinetics at $335{ }^{\circ} \mathrm{C}$ of $1 \mathrm{~h}$ milled $\mathrm{MgH}_{2}$ without and with $5 \mathrm{~mol} \% \mathrm{MgF}_{2}$.

(a) First absorption under $1000 \mathrm{kPa} \mathrm{H}_{2}$; (b) desorption under $100 \mathrm{kPa} \mathrm{H}_{2}$.

It is observed that at $335^{\circ} \mathrm{C}$ under $1000 \mathrm{kPa} \mathrm{H}_{2}$ pressure $\mathrm{MgH}_{2}+5 \mathrm{~mol}_{\%} \mathrm{MgF}_{2}$ system absorbs $6.2 \mathrm{wt} \%$ hydrogen in $30 \mathrm{~min}$ in comparison to only $5.3 \mathrm{wt} \%$ absorption by pure $\mathrm{MgH}_{2}$. This shows a large improvement in absorption capacity is achieved, yielding $92 \%$ of the theoretical capacity in comparison to $70 \%$ for the pure $\mathrm{MgH}_{2}$. In addition, significant improvement in desorption kinetics is achieved with complete desorption of the hydride phase in less than $20 \mathrm{~min}$ in presence of $\mathrm{MgF}_{2}$. Thus, the beneficial effect of $\mathrm{MgF}_{2}$ is clearly evident on the hydriding/dehydriding aspect of $\mathrm{MgH}_{2}$.

Figure 3 shows the diffraction patterns of the doped sample in its desorbed and reabsorbed states. The desorbed pattern shows a small amount of un-desorbed $\mathrm{MgH}_{2}$. The interesting fact is that $\mathrm{MgF}_{2}$ is still present in the sample. This could be expected because it is known that for $\mathrm{MgH}_{2}$-transition metal (TM) fluoride systems, milling or dehydrogenation induces the formation of $\mathrm{MgF}_{2}$ and $\mathrm{TM}$ hydride [4,11]. Thus, $\mathrm{MgF}_{2}$ is a stable compound and does not react to form $\mathrm{MgH}_{2}$.

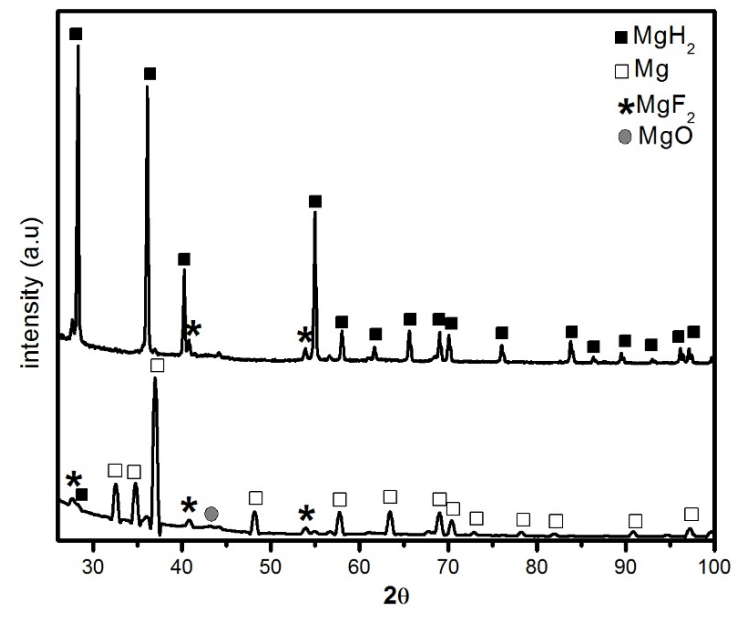

Figure 3. XRD patterns of $\mathrm{MgH}_{2}+5 \mathrm{~mol} \% \mathrm{MgF}_{2}$ (a) after desorption at $335^{\circ} \mathrm{C}$ under $100 \mathrm{kPa} \mathrm{H}_{2}$ and (b) after re-hydrogenation at $335^{\circ} \mathrm{C}$ under $1000 \mathrm{kPa} \mathrm{H}_{2}$. 
This is confirmed by the diffraction pattern of fully hydrided sample. The phases present are $\mathrm{MgH}_{2}$ and $\mathrm{MgF}_{2}$ along with small amount of unreacted $\mathrm{Mg}$. Compared to the patterns of Figure 1 we see that the peaks of patterns of Figure 3 are not as broad, implying that the crystallite size increased. From Rietveld analysis we found that the crystallite size of $\mathrm{Mg}$ in the dehydrided pattern is $49.1 \pm 0.8 \mathrm{~nm}$ while the crystallite size of $\mathrm{MgH}_{2}$ in the reabsorbed pattern is $64 \pm 2 \mathrm{~nm}$. This shows that there is grain growth compared to the as-milled sample. This may be due to the high temperature of hydrogenation and also because of desorption/absorption itself.

Figure 4 shows the SEM images of $\mathrm{MgH}_{2}+5 \mathrm{~mol} \% \mathrm{MgF}_{2}$ composite in (Figure 4a) desorbed state and (Figure 4b) after re-hydrogenation at $335{ }^{\circ} \mathrm{C}$ in comparison with pure $\mathrm{MgH}_{2}$ (Figure 4c). The images show that ball milling with additive leads to effective decrease in particle size. In addition, energy dispersive X-ray (EDX) mapping done at higher magnification (Figure 5) shows that agglomerates consist of smaller $\mathrm{MgH}_{2}$ particles and additive.

Elemental mapping made on $\mathrm{MgH}_{2}+5 \mathrm{~mol} \% \mathrm{MgF}_{2}$ in both the desorbed state (Figure $5 \mathrm{a}$ ) and re-hydrogenated state (Figure $5 b$ ) confirms homogenous distribution of $\mathrm{MgF}_{2}$.

High energy milling leads to uniform dispersion of $\mathrm{MgF}_{2}$ phase in $\mathrm{MgH}_{2}$ matrix which may act as a catalytic layer and contributes in improving sorption properties. Chemical analysis performed by EDX spectroscopy during transmission electron microscopy (TEM) investigation of the desorbed sample gave the average atomic composition of different elements as $9.8 \% \mathrm{O}, 14.7 \% \mathrm{~F}$ and $75.7 \% \mathrm{Mg}$ which is very close to the nominal composition ( $86 \% \mathrm{Mg}$ and $14 \% \mathrm{~F})$. The presence of oxygen in EDX pattern in comparison to its small trace in XRD pattern could be due to small crystallite size of $\mathrm{MgO}$ making it peak difficult to distinguish from the background. A similar EDX investigation was performed on a sample that has been submitted to five dehydrogenation/hydrogenation cycles. Because abundances vary from point to point, we average over four different localisations. We found that, after cycling, the atomic composition of different elements was $15 \% \pm 4 \% \mathrm{O}, 11 \% \pm 4 \% \mathrm{~F}$ and $74 \% \pm 6 \% \mathrm{Mg}$. Within experimental error, these values are similar to the ones before cycling. However, this may be an indication that cycling induces a loss of $\mathrm{MgF}_{2}$ and increase of $\mathrm{MgO}$. Typical TEM micrographs presented in Figure 6 shows the morphology of the desorbed sample.

The image shows presence of large number of particles agglomerated together with no visibility clear particle boundaries. These observations are quite similar to those reported recently by Grzech et al. [13]. High resolution pictures taken over region-1 in Figure 6 and its corresponding selected area electron diffraction (SAED) patterns shows reflections at $d$-spacing 2.45, 1.90, 1.60, 1.36 and $1.22 \AA$ which are characteristic of $\mathrm{Mg}(101),(102),(110),(112)$ and (202) planes respectively along with reflections at $\mathrm{d}$ values 2.10 and $1.48 \AA$, corresponding to $\mathrm{MgO}(200)$ and (220) planes. Thus, the surface consists of small crystallites of $\mathrm{MgO}$ (forming well defined ring and represented by red rings) surrounding the large crystallites of $\mathrm{Mg}$ (seen as discontinuous spots and represented by white rings). While the multiple SAED patterns acquired from the region- 2 were well indexed as a mixture of large crystallite $\mathrm{Mg}$ and small crystallite of $\mathrm{MgF}_{2}$ (seen as well-defined rings and colored yellow). The absence of oxide in region- 2 is evidence that presence of fluoride limits $\mathrm{MgO}$ only to the surface. Both structural and morphological studies support the presence of $\mathrm{MgF}_{2}$ phase even after complete hydrogen absorption/desorption cycle at $335^{\circ} \mathrm{C}$. 

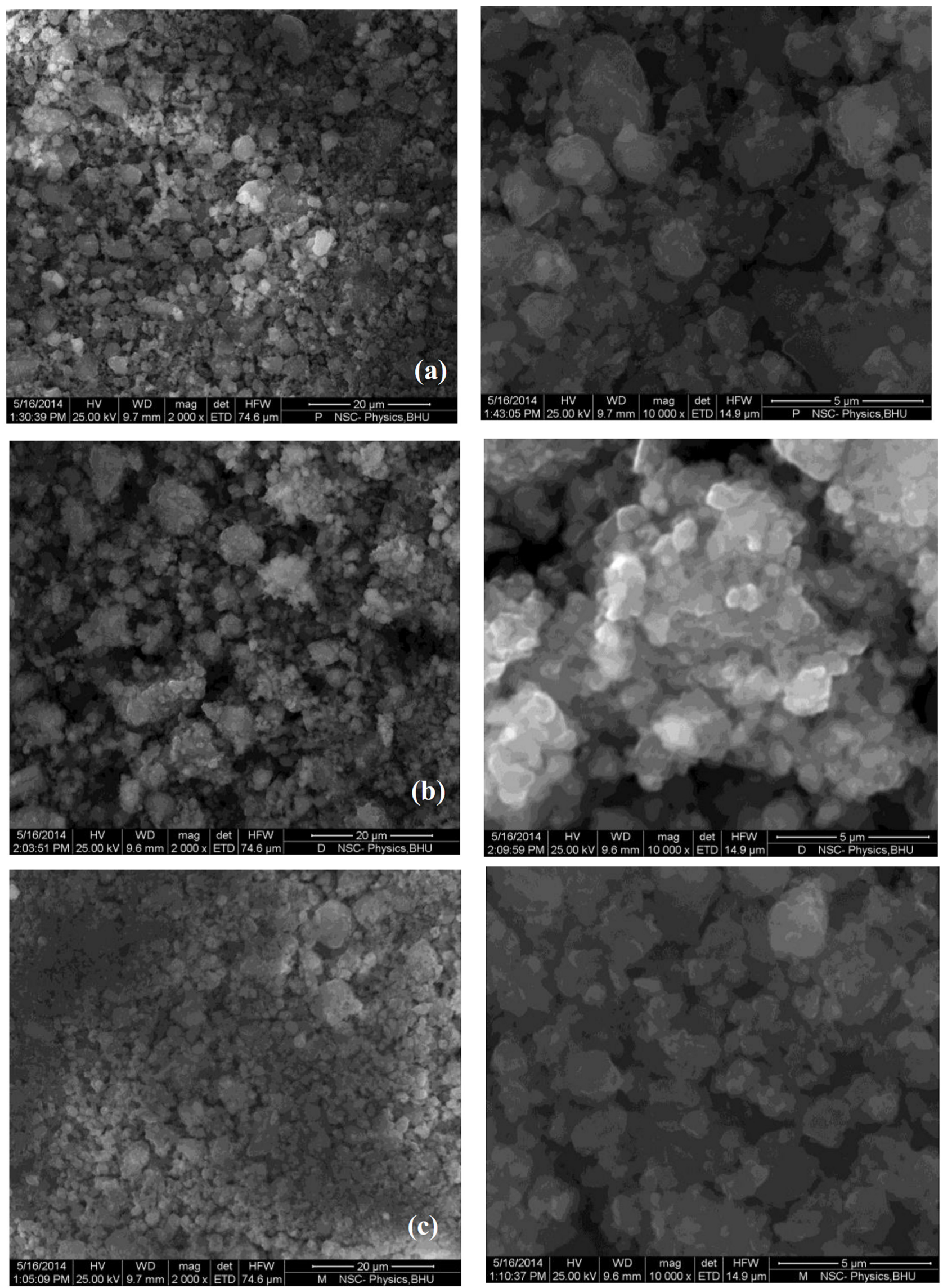

Figure 4. $\mathrm{SEM}$ images for $\mathrm{MgH}_{2}+5 \mathrm{~mol} \% \mathrm{MgF}_{2}$ in (a) desorbed state and (b) re-hydrogenated state in comparison to (c) pure $\mathrm{MgH}_{2}$. 

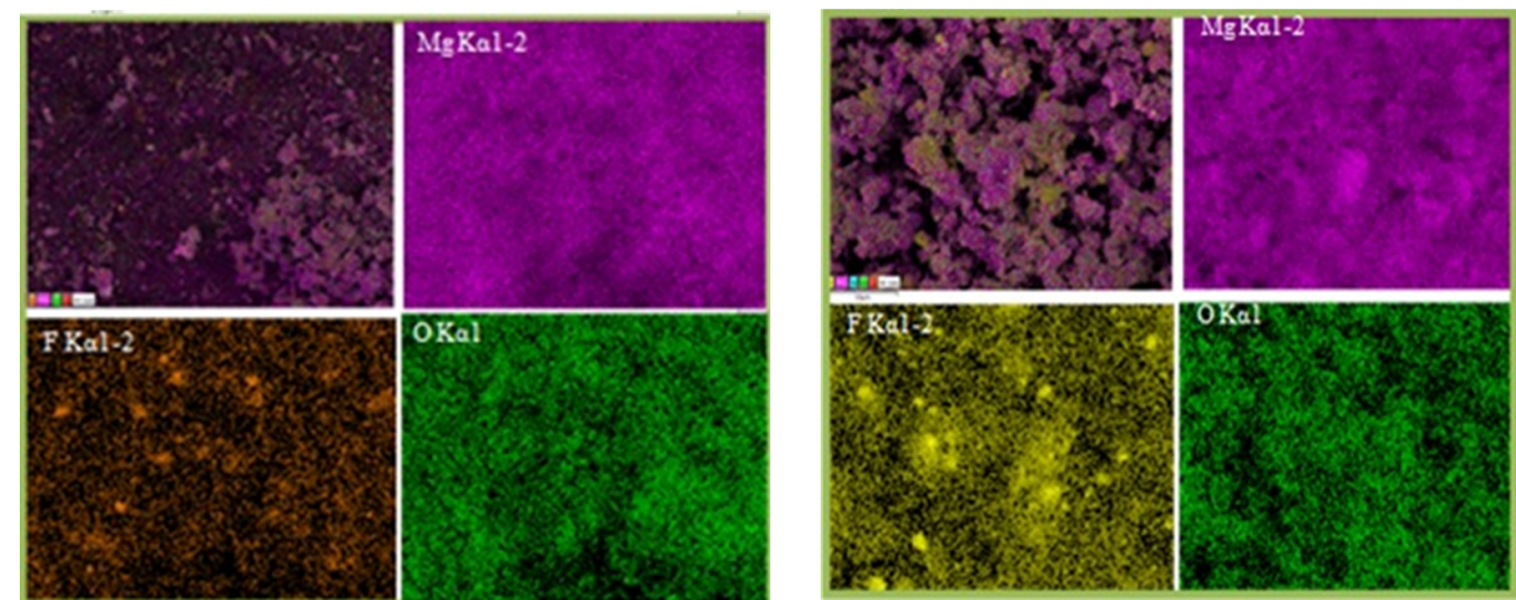

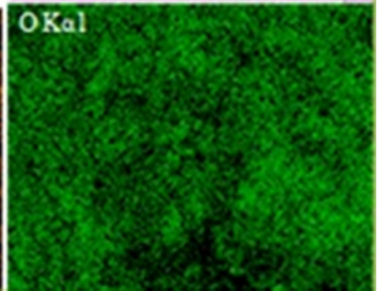

(a)

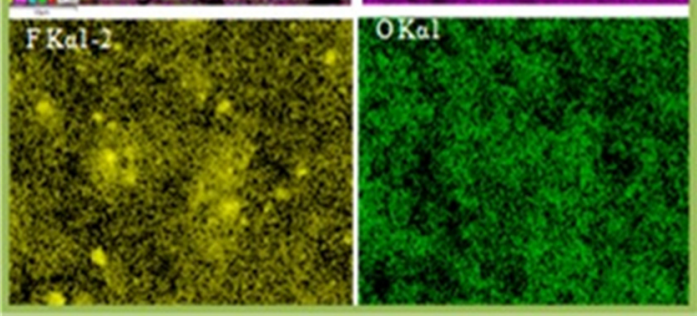

(b)

Figure 5. Elemental mapping showing particle morphology and distribution of $1 \mathrm{~h}$ milled $\mathrm{MgH}_{2}+5 \mathrm{~mol} \%$ $\mathrm{MgF}_{2}$ : (a) after desorption and (b) after re-hydrogenation at $335^{\circ} \mathrm{C}$.
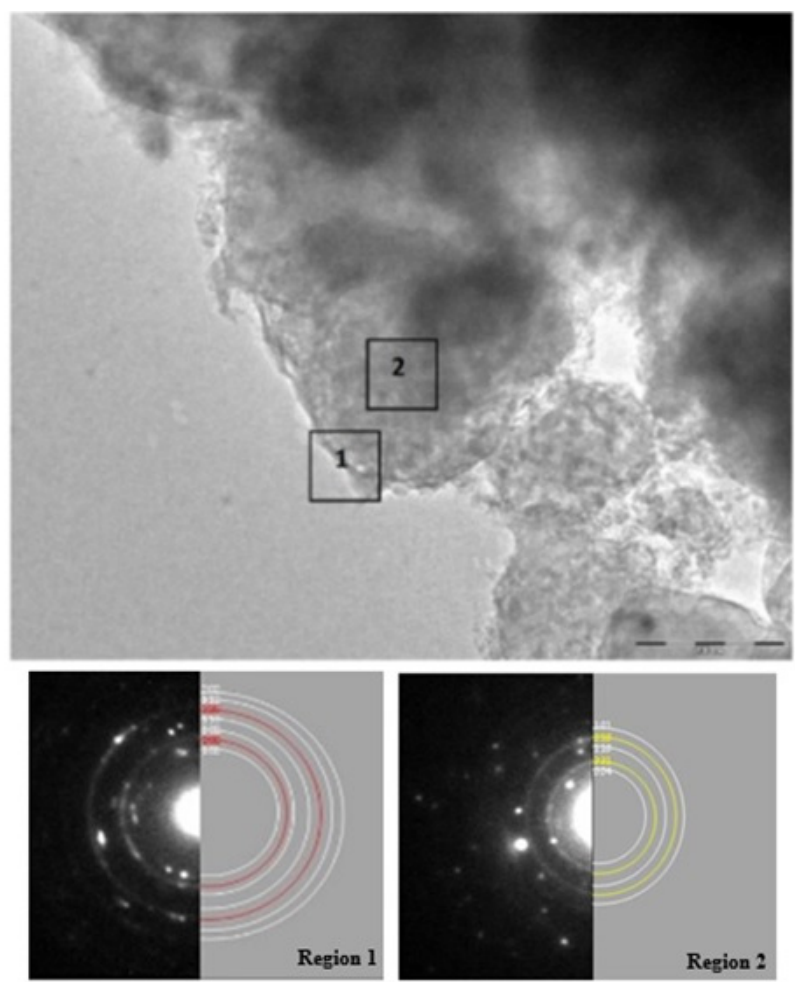

Figure 6. Transmission electron microscopy (TEM) micrograph of $\mathrm{MgH}_{2}+5 \mathrm{~mol} \% \mathrm{MgF}_{2}$ sample after desorption at $335^{\circ} \mathrm{C}$ with selected area electron diffraction (SAED) patterns and simulations. Region 1 is composed of $\mathrm{Mg}$ (white rings) covered with $\mathrm{MgO}$ layer (red rings) in simulated data while Region 2 shows diffraction rings corresponding to $\mathrm{Mg}$ (white rings) and $\mathrm{MgF}_{2}$ (yellow rings).

\subsection{Hydrogenation Characteristics of $\mathrm{MgH}_{2}+5 \mathrm{~mol} \% \mathrm{MgF}$ at Lower Temperatures}

The catalytic effect of $5 \mathrm{~mol} \% \mathrm{MgF}_{2}$ on hydrogen sorption properties of $\mathrm{MgH}_{2}$ was further investigated at lower temperatures. Figure 7 shows the absorption kinetics at 335, 310, 285 and $145{ }^{\circ} \mathrm{C}$ under $1000 \mathrm{kPa}$ of hydrogen. 
absorption cyc1 at $1000 \mathrm{kPa}$

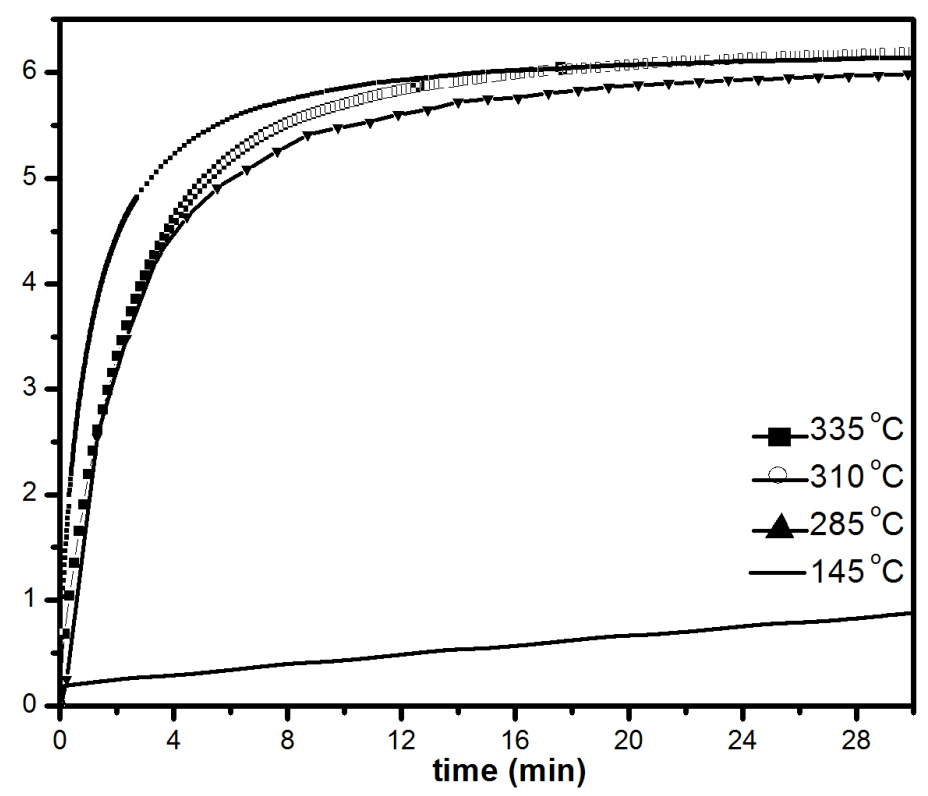

Figure 7. First absorption under $1000 \mathrm{kPa} \mathrm{H}_{2}$ at different temperatures of $1 \mathrm{~h}$ milled $\mathrm{MgH}_{2}+5 \mathrm{~mol} \%$ $\mathrm{MgF}_{2}$. The insert is a compete absorption curve at $145^{\circ} \mathrm{C}$.

It should be pointed out that the samples were initially desorbed at $335{ }^{\circ} \mathrm{C}$ in order to ensure that full desorption was achieved before all absorption measurements. We notice only a slight loss in absorption capacity with reduction of temperature from $335^{\circ} \mathrm{C}\left(6.2 \mathrm{wt} \% \mathrm{H}_{2}\right)$ to $285^{\circ} \mathrm{C}\left(5.8 \mathrm{wt} \% \mathrm{H}_{2}\right)$. As seen in Figure 7, there was slight loss in kinetics and capacity in the temperature range $335-285^{\circ} \mathrm{C}$ with the material reaching its complete capacity in less than $30 \mathrm{~min}$. However, at $145^{\circ} \mathrm{C}$, the kinetics are much slower, but after $20 \mathrm{~h}$, a capacity of $5.5 \mathrm{wt} \%$ is reached, as shown in Figure $7 \mathrm{~b}$. Desorption kinetic under $100 \mathrm{kPa} \mathrm{H}_{2}$ at 285,310 and $335^{\circ} \mathrm{C}$ are shown in Figure 8 .

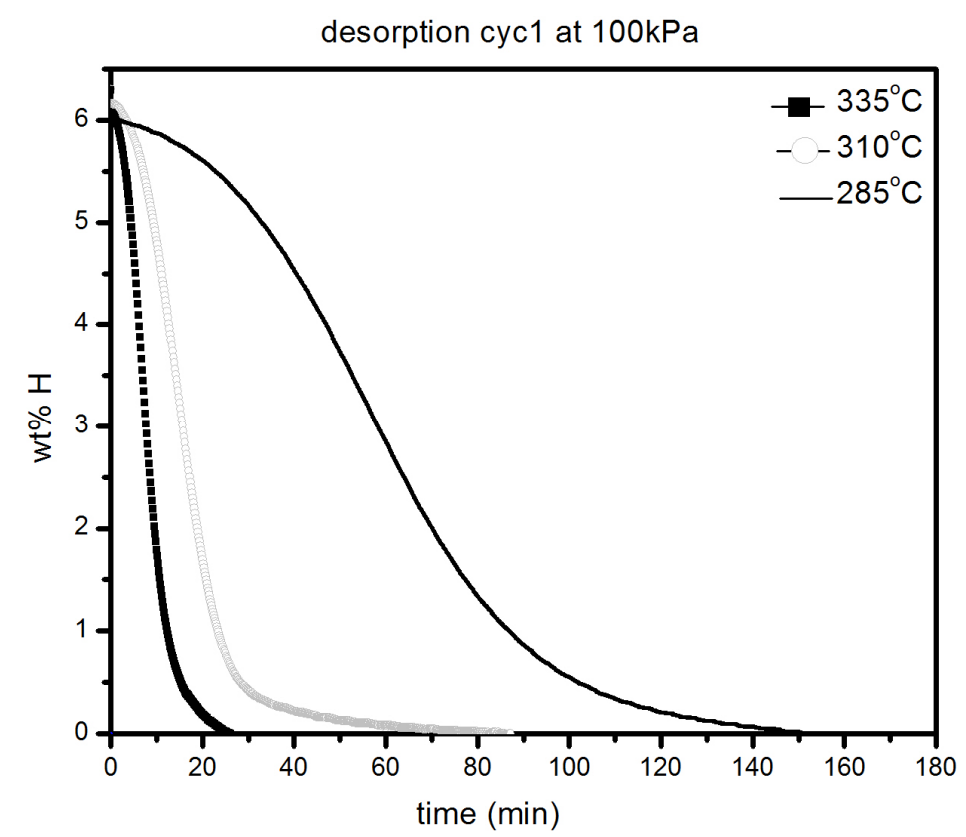

Figure 8. Desorption under $100 \mathrm{kPa} \mathrm{H}_{2}$ at different temperatures of $1 \mathrm{~h}$ milled $\mathrm{MgH}_{2}+5 \mathrm{~mol} \% \mathrm{MgF}_{2}$. 
As expected, the kinetics are getting slower as temperature decreases but is still relatively fast even at $285{ }^{\circ} \mathrm{C}$ were complete desorption takes place in less than $3 \mathrm{~h}$. These results reveal that even by sole addition of alkaline metal fluorides, improvements in hydrogenation characteristics of magnesium hydride can be achieved.

\subsection{Cyclic Stability of $\mathrm{MgH}_{2}+5 \mathrm{~mol} \% \mathrm{MgF}_{2}$ at $\mathrm{T}=310^{\circ} \mathrm{C}$}

Micro structural results have confirmed that $\mathrm{MgF}_{2}$ phase does not decompose and no new phase formation occurs during hydrogen absorption/desorption measurements for $\mathrm{MgH}_{2}+5 \mathrm{~mol} \% \mathrm{MgF}_{2}$ system. Therefore, cyclic performance of catalyzed magnesium hydride was examined at moderate operating temperature of $310^{\circ} \mathrm{C}$ at pressure of $1000 \mathrm{kPa}$ (for absorption) and $10 \mathrm{kPa}$ (for desorption) to evaluate performance stability. Prior to the measurements the sample was completely desorbed at $335^{\circ} \mathrm{C}$. Figure 9 shows that the absorption capacity goes down from $5.9 \mathrm{wt} \%$ in first cycle to $5.6 \mathrm{wt} \%$ in the 10 th cycle.

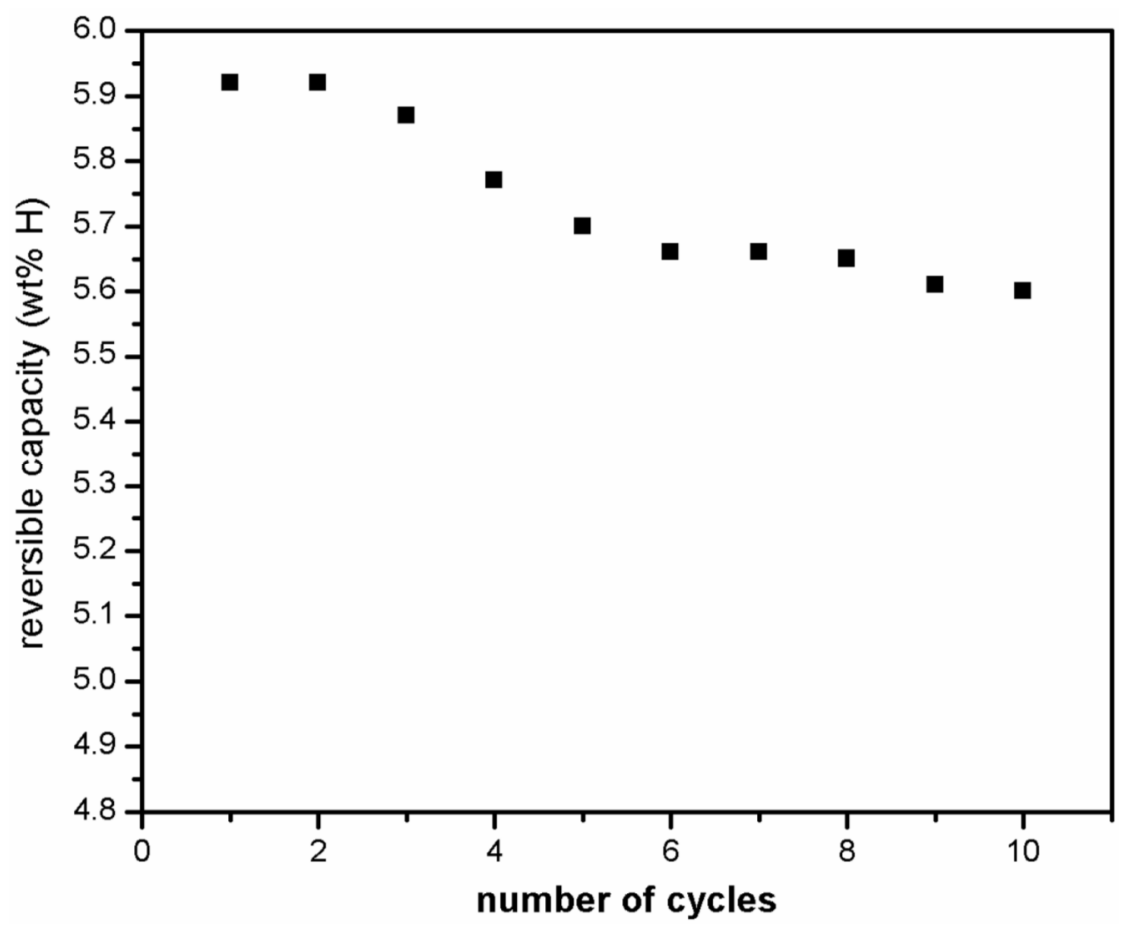

Figure 9. Hydrogen absorption kinetics at $310{ }^{\circ} \mathrm{C}$ under $1000 \mathrm{kPa}$ of hydrogen of ball milled $\mathrm{MgH}_{2}+5 \mathrm{~mol} \% \mathrm{MgF}_{2}$ for 10 cycles.

The observed loss of $0.3 \mathrm{wt} \%$ in capacity was reached within the first five cycles and thereafter the maximum capacity achieved by the system is more or less stabilized. These results show that magnesium hydride exhibits good hydrogen storage capacity and cyclic stability when magnesium fluoride is used as catalyst in comparison to the use of transition metal fluoride like $\mathrm{NbF}_{5} \mathrm{or}_{\mathrm{ZrF}_{4}}$ where sharp decline in storage capacity was observed by Malka et al. [14] in the first 10 hydrogenation cycles recorded at $325^{\circ} \mathrm{C}$. X-ray diffraction patterns of the sample taken after 1st and 10th desorption cycle are presented in Figure 10. It shows that the $\beta-\mathrm{MgH}_{2}$ phase and the catalytic material remain intact while small increase in content of $\mathrm{MgO}$ occurs. Thus, the growth of the $\mathrm{MgO}$ layer is mostly responsible for an observed loss in capacity. 


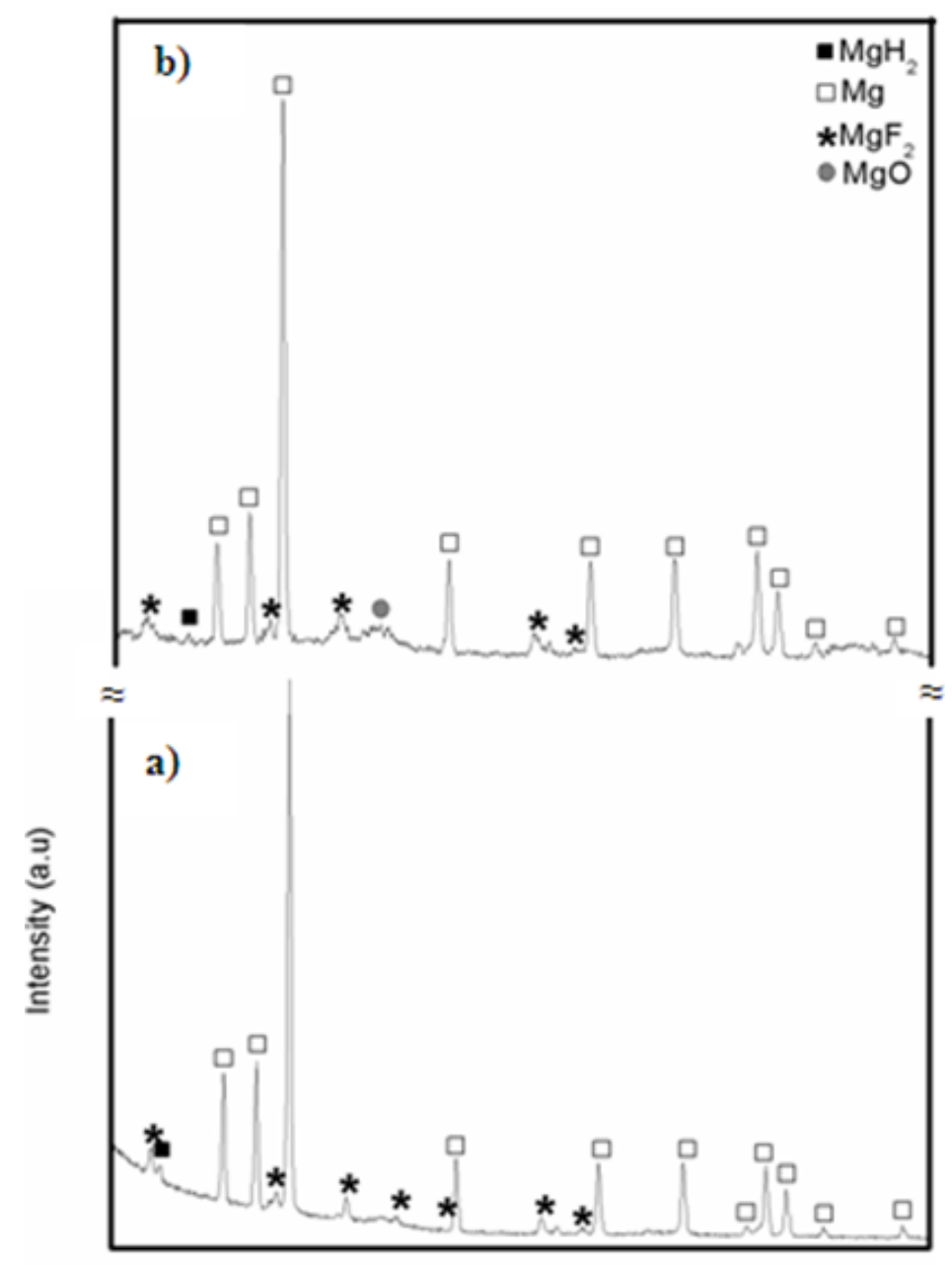

20

Figure 10. X-ray diffraction patterns of ball milled $\mathrm{MgH}_{2}+5 \mathrm{~mol} \% \mathrm{MgF}_{2}$ after (a) one desorption and (b) 10 desorption cycles at $310^{\circ} \mathrm{C}$.

\section{Discussion}

The structural and hydrogenation results suggest that hydrogen absorption/desorption kinetics of $\mathrm{MgF}_{2}$ doped $\mathrm{MgH}_{2}$ is relatively slower than that attained with transition metal fluorides $\left(\mathrm{TmF}=\mathrm{TiF}_{3}, \mathrm{ZrF}_{4}, \mathrm{NbF}_{5}, \mathrm{TaF}_{5}\right)$. This could be explained by the presence of only one catalytically active phase in the present case $\left(\mathrm{MgF}_{2}\right)$ while two active phases are present when transition metal fluorides are used as additives. More explicitly, upon dehydrogenation the following reaction takes place in the present case.

$$
\mathrm{MgH}_{2}+\mathrm{MgF}_{2} \rightarrow \mathrm{Mg}+\mathrm{MgF}_{2}+\mathrm{H}_{2}
$$

While, as reported by Ma et al. [11], when transition metal fluoride is added the reaction taking place is:

$$
3 \mathrm{MgH}_{2}+2 \mathrm{TiF}_{3} \rightarrow 3 \mathrm{MgF}_{2}+2 \mathrm{TiH}_{2}+\mathrm{H}_{2}
$$

As $\mathrm{TiH}_{2}$ possess more negative enthalpy formation $(-136 \mathrm{~kJ} / \mathrm{mol})$ than $\mathrm{MgH}_{2}(-75 \mathrm{~kJ} / \mathrm{mol})$ it will remain as a stable phase during desorption of $\mathrm{MgH}_{2}$ in later cycles [13]. Furthermore, presence and concentration of $\mathrm{TiH}_{2}$ phase would increase on multiple absorption/desorption cycling, which results in reduction of overall storage capacity. In addition, the transition metal fluoride is very sensitive to atmospheric conditions. Ball milled $\mathrm{MgH}_{2}+\mathrm{TM}$-fluoride samples require oxygen and moisture level to be less than $0.1 \mathrm{ppm}$ for obtaining good hydrogenation results $[7,9,11,15]$. 
Additionally, even in the desorbed state the material is pyrophoric, which makes it difficult to handle. Moreover, transition metals are much heavier than magnesium thereby increasing the mass of entire system. It thus seems more practical to use $\mathrm{MgF}_{2}$ as a doping agent to increase the hydrogenation/dehydrogenation kinetics than transition metal fluorides.

\section{Experimental Section}

The starting materials $\mathrm{MgH}_{2}$ (99.8\% purity) and $\mathrm{MgF}_{2}$ (99.9\% purity) purchased from Alfa Aesar (Ward Hill, MA, USA) were vacuum annealed for few hours at $80{ }^{\circ} \mathrm{C}$ before using them for experiments. Afterwards, $\mathrm{MgH}_{2}$ powder with 2, 5, and $10 \mathrm{~mol} \% \mathrm{MgF}_{2}$, was milled under $\mathrm{Ar}$ atmosphere using Fritsch P4 planetary mill (Idar-Oberstein, Germany) with ball to powder ratio of 50:1 at a crucible rotation speed of $220 \mathrm{rpm}$. Milling was done for $60 \mathrm{~min}$ with $15 \mathrm{~min}$ rest after every $15 \mathrm{~min}$ of milling. The final milled products were handled in a glove box with oxygen and moisture level below $0.1 \mathrm{ppm}$. Initial hydrogen desorption curves taken at $335{ }^{\circ} \mathrm{C}$ under $100 \mathrm{kPa}$ $\mathrm{H}_{2}$ pressure showed that with $2 \mathrm{~mol} \%$ catalytic material the kinetics was too slow which could be improved by increasing the additive content to $5 \mathrm{~mol} \%$. Further increase in concentration of catalytic material to $10 \mathrm{~mol} \%$ didn't cause any significant change in kinetics. Therefore, $\mathrm{MgF}_{2}$ concentration was restricted to $5 \mathrm{~mol} \%$ for further investigation.

The hydrogenation characteristics were measured on homemade Sievert-type apparatus and the cyclic studies were made on an automated-four channel apparatus called Multi Channel Hydride Evaluation System from Advanced Materials Corporation, Petersburg, VA, USA. Approximately $400 \mathrm{mg}$ of powder was placed in a sample cell and completely desorbed under dynamic vacuum at $335{ }^{\circ} \mathrm{C}$ prior to any measurement. Thereafter all measurements were made under $1000 \mathrm{kPa}$ $\mathrm{H}_{2}$ pressure for absorption and $100 \mathrm{kPa} \mathrm{H}_{2}$ pressure for desorption at temperatures ranging from $335^{\circ} \mathrm{C}$ to $145^{\circ} \mathrm{C}$. X-ray diffraction was performed using Bruker D8 Focus X-Ray apparatus (Bruker, Madison, WI, USA) with $\mathrm{CuK} \alpha$ radiation. Phase abundances were evaluated from Rietveld method using Topas software [16]. Small quantity of milled $\mathrm{MgH}_{2}+5 \mathrm{~mol} \% \mathrm{MgF}_{2}$ (a) after desorption at $325^{\circ} \mathrm{C}$ and (b) after rehydrogenation under $1000 \mathrm{kPa} \mathrm{H}_{2}$ was characterized for morphological studies with chemical analysis using JEOL JSM-5500 scanning electron microscope (JEOL, Tokyo, Japan). The sample was filled in air tight bottles and taken to SEM-EDX lab were they were slightly exposed to air for loading in SEM chamber. TEM analysis was performed on FEI: Technai $20 \mathrm{G}^{2}$ electron microscope (FEI, Hillsboro, OR, USA), operating at $200 \mathrm{kV}$ accelerating voltage. TEM samples were prepared by dry dispersion of the powder onto a carbon substrate supported by copper TEM grid. This was done in an argon glove box before the TEM session, and the prepared sample was sealed by covering with parafilm tape to be carried to TEM lab. The sample was exposed to air for short duration during loading onto the TEM holder. Thus, partially transformed samples were characterised using scanning and transmission electron microscopy.

\section{Conclusions}

This investigation showed that magnesium fluoride could significantly influence the hydrogen sorption properties of magnesium hydride. It has been shown that $\mathrm{MgF}_{2}$ additive acts as a catalyst for $\mathrm{MgH}_{2}$, thereby improving its hydrogenation/dehydrogenation kinetics. These kinetic improvements are due to the presence of chemically stable $\mathrm{MgF}_{2}$ powder well mixed in $\mathrm{MgH}_{2}$ matrix and $\mathrm{MgO}$ layer being limited only to the surface. Cyclic stability reveals that $5 \mathrm{~mol} \% \mathrm{MgF}_{2}$ helps to accelerate the reversible kinetics of $\mathrm{MgH}_{2}$ with higher capacity in comparison to other transition metal fluoride catalysts. This is probably due to the persistence of $\mathrm{MgF}_{2}$ phase during hydrogen cycling. These results suggest that owing to its fast sorption properties, low sensitivity to atmospheric conditions and easy handling ability, this material can be used in applications where operation at relatively high temperature is not considered a significant issue.

Acknowledgments: Pragya Jain would like to thank University Grant Commission (UGC) for the Dr. D.S. Kothari post-doctoral fellowship to carry out this work. 
Author Contributions: Study conception and design: Pragya Jain, Jacques Huot; Acquisition of data: Pragya Jain, Viney Dixit; Analysis and interpretation of data: Pragya Jain, Jacques Huot, Onkar N. Srivastava; Drafting of manuscript: Pragya Jain, Ankur Jain, Jacques Huot; Critical revision: Pragya Jain, Jacques Huot.

Conflicts of Interest: The authors declare no conflict of interest.

\section{References}

1. Jain, I.P.; Lal, C.; Jain, A. Hydrogen storage in Mg: A most promising material. Int. J. Hydrog. Energy 2010, 35, 5133-5144. [CrossRef]

2. Wu, Z.; Allendorf, M.D.; Grossman, J.C. Quantum Monte Carlo Simulation of Nanoscale $\mathrm{MgH}_{2} \mathrm{Cluster}$ Thermodynamics. J. Am. Chem. Soc. 2009, 131, 13918-13919. [CrossRef] [PubMed]

3. Dornheim, M.; Eigen, N.; Barkhordarian, G.; Klassen, T.; Bormann, R. Tailoring Hydrogen Storage Materials Towards Application. Adv. Eng. Mater. 2006, 8, 377-385. [CrossRef]

4. Hanada, N.; Ichikawa, T.; Fujii, H. Catalytic effect of nanoparticle 3d-transition metals on hydrogen storage properties in magnesium hydride $\mathrm{MgH}_{2}$ prepared by mechanical milling. J. Phys. Chem. B 2005, 109, 7188-7194. [CrossRef] [PubMed]

5. Aguey-Zinsou, K.F.; Ares Fernandez, J.R.; Klassen, T.; Bormann, R. Effect of $\mathrm{Nb}_{2} \mathrm{O}_{5}$ on $\mathrm{MgH}_{2}$ properties during mechanical milling. Int. J. Hydrog. Energy 2007, 32, 2400-2407. [CrossRef]

6. Ma, L.P.; Wang, P.; Cheng, H.M. Improving hydrogen sorption kinetics of $\mathrm{MgH}_{2}$ by mechanical milling with $\mathrm{TiF}_{3}$. J. Alloys Compd. 2007, 432, L1-L4. [CrossRef]

7. Yavari, A.R.; LeMoulec, A.; de Castro, F.R.; Deledda, S.; Friedrichs, O.; Botta, W.J.; Vaughan, G.; Klassen, T.; Fernandez, A.; Kvick, Å. Improvement in $\mathrm{H}$-sorption kinetics of $\mathrm{MgH}_{2}$ powders by using Fe nanoparticles generated by reactive $\mathrm{FeF}_{3}$ addition. Scr. Mater. 2005, 52, 719-724. [CrossRef]

8. Deledda, S.; Borissova, A.; Poinsignon, C.; Botta, W.J.; Dornheim, M.; Klassen, T. H-sorption in $\mathrm{MgH}_{2}$ nanocomposites containing Fe or Ni with fluorine. J. Alloys Compd. 2005. [CrossRef]

9. Malka, I.E.; Pisarek, M.; Czujko, T.; Bystrzycki, J. A study of the $\mathrm{ZrF}_{4}, \mathrm{NbF}_{5}, \mathrm{TaF}_{5}$, and $\mathrm{TiCl}_{3}$ influences on the $\mathrm{MgH}_{2}$ sorption properties. Int. J. Hydrog. Energy 2011, 36, 12909-12917. [CrossRef]

10. Ivanov, E.; Konstanchuk, I.; Bokhonov, B.; Boldyrev, V. Hydrogen interaction with mechanically alloyed magnesium-salt composite materials. J. Alloys Compd. 2003, 359, 320-325.

11. Ma, L.-P.; Wang, P.; Cheng, H.-M. Hydrogen sorption kinetics of $\mathrm{MgH}_{2}$ catalyzed with titanium compounds. Int. J. Hydrog. Energy 2010, 35, 3046-3050. [CrossRef]

12. Soni, P.R. Mechanical Alloying: Fundamentals and Applications; Cambridge International Science Publishing: Cambridge, UK, 2000; p. 160.

13. Grzech, A.; Lafont, U.; Magusin, P.; Mulder, F.M. Microscopic Study of $\mathrm{TiF}_{3}$ as Hydrogen Storage Catalyst for $\mathrm{MgH}_{2}$. J. Phys. Chem. C 2012, 116, 26027-26035. [CrossRef]

14. Malka, I.E.; Bystrzycki, J.; Płociński, T.; Czujko, T. Microstructure and hydrogen storage capacity of magnesium hydride with zirconium and niobium fluoride additives after cyclic loading. J. Alloys Compd. 2011, 509, S616-S620. [CrossRef]

15. Jin, S.-A.; Shim, J.-H.; Cho, Y.W.; Yi, K.-W. Dehydrogenation and hydrogenation characteristics of $\mathrm{MgH}_{2}$ with transition metal fluorides. J. Power Sources 2007, 172, 859-862. [CrossRef]

16. Topas V4: General Profile and Structure Analysis Software for Powder Diffraction Data; Bruker_AXS: Karlsruhe, Germany, 2008.

(C) 2015 by the authors; licensee MDPI, Basel, Switzerland. This article is an open access article distributed under the terms and conditions of the Creative Commons by Attribution (CC-BY) license (http://creativecommons.org/licenses/by/4.0/). 